Article

\title{
Controlling Persister and Biofilm Cells of Gram-Negative Bacteria with a New 1,3,5-Triazine Derivative
}

\author{
Ali Adem Bahar ${ }^{1,2, \dagger}$, Zhigang Liu ${ }^{3, \dagger}$, Meagan Garafalo ${ }^{1,2}$, Neville Kallenbach ${ }^{3, *}$ \\ and Dacheng Ren ${ }^{1,2,4,5, *}$
}

1 Department of Biomedical and Chemical Engineering, Syracuse University, Syracuse, NY 13244, USA; E-Mails: abahar@syr.edu (A.A.B.); meagan8390@yahoo.com (M.G.)

2 Syracuse Biomaterials Institute, Syracuse University, Syracuse, NY 13244, USA

3 Department of Chemistry, New York University, New York, NY 10003, USA; E-Mail: zl264@nyu.edu

4 Department of Civil and Environmental Engineering, Syracuse University, Syracuse, NY 13244, USA

5 Department of Biology, Syracuse University, Syracuse, NY 13244, USA

$\dagger$ These authors contributed equally to this work.

* Authors to whom correspondence should be addressed; E-Mails: nrk1@nyu.edu (N.K.), dren@syr.edu (D.R.); Tel.: +1-315-443-4409 (D.R.); Fax: +1-315-443-9175 (D.R.).

Academic Editor: Jean Jacques Vanden Eynde

Received: 28 July 2015 / Accepted: 28 September 2015 /Published: 10 October 2015

\begin{abstract}
Infections caused by multidrug-resistant bacteria have been on the rise. This important issue presents a great challenge to the healthcare system and creates an urgent need for alternative therapeutic agents. As a potential solution to this problem, antimicrobial peptides (AMPs) have attracted increasing attention due to their broad spectrum of targeted microbes. However, most AMPs are expensive to synthesize, have relatively high cytotoxicity to mammalian cells, and are susceptible to proteolytic degradation. In order to overcome these limitations, novel synthetic AMPs are desired. Using 1,3,5-triazine (TN) as a template, several combinatorial libraries with varying cationic charge and lipophilicity were designed and screened by the Kallenbach lab. From this screening, TN-5 was identified as a potent lead. In the present study, this compound was tested for its antimicrobial activities on Escherichia coli and Pseudomonas aeruginosa. In addition to regular planktonic cells, the effects on biofilms and persister cells (metabolically inactive and antibiotic tolerant subpopulation) were also investigated. TN-5 was found to have a minimum inhibitory concentration (MIC) of $12.8 \mu \mathrm{M}$ for both species and kill regular planktonic cells of both species dose dependently. TN-5 is also
\end{abstract}


effective against persister cells of both $E$. coli and $P$. aeruginosa. The killing of biofilm cells of the mucoid $P$. aeruginosa PDO300 was enhanced by alginate lyase.

Keywords: antimicrobial peptide; biofilm; persister cells; TN-5; Escherichia coli; Pseudomonas aeruginosa

\section{Introduction}

Since the discovery of penicillin in 1928 [1] and the achievement of economical production of this antibiotic in the 1940s [2], the use of antibiotics has been a crucial step in controlling infectious diseases with numerous lives saved [3]. However, the emergence and spread of antibiotic resistant microorganisms have rendered many antibiotics ineffective [4]. Such rapid development of multidrug resistant bacteria coupled with the insufficient investment in antimicrobial research has led to a concerning decline in effective therapies against bacterial infections, which presents a serious public health problem [5].

In addition to antibiotic resistance based on drug resistance genes [6], bacteria also exhibit high level antibiotic tolerance by forming persister cells (dormant subpopulation of phenotypic variants [7] and biofilms (surface attached structures with bacterial cells embedded in an extracellular matrix secreted by attached cells [8]). Persister cells and biofilms are not based on drug resistance genes; however, they allow bacteria to survive the treatment with potent antibiotics and facilitate the development of drug resistant strains through mutation and horizontal gene transfer [9].

According to the U.S. Centers for Diseases Control and Prevention, 65\% of all infections in developed countries are caused by biofilms [10]. The biofilm matrix serves as a protective barrier, making bacterial cells more tolerant to antibiotics as well as host defense [11]. Biofilms are also enriched in persister cells. Thus, even if an antibiotic can penetrate the biofilm matrix, it might only kill normal cells within a biofilm population. After the course of antibiotic treatment, persister cells revive and repopulate the biofilm, which in turn causes an infection to relapse [10].

An additional concern with biofilms of Pseudomonas aeruginosa is their ability to convert to mucoid variants [12]. A mucoid strain is characterized by overproduction of the exopolysaccharide alginate, with increased tolerance to some antibiotics [13] and phagocytosis by human macrophages [14], as well as enhanced protection from dehydration [15]. In cystic fibrosis patients, the leading cause of mortality is a respiratory failure due to chronic lung infection with $P$. aeruginosa strains that undergo mucoid conversion [12]. Mucoid isolates typically coincide with persistent chronic infection in cystic fibrosis patients.

The challenges of drug tolerant infections have created an urgent need for new antimicrobials and treatment strategies. Recent research has shown the great potential of antimicrobial peptides (AMPs) as a class of powerful agents against both Gram-positive and Gram-negative bacteria [16,17]. A wide range of AMPs are naturally produced by the innate immune system of multicellular organisms in response to infections [18]. These AMPs are a unique group of molecules with a varying number of amino acids (generally from 12 to 50), including positively charged residues (such as arginine, lysine, 
or histidine) and a large proportion of hydrophobic residues. In humans, AMPs are found mainly in the tissues and organs that are exposed to airborne pathogens [19].

The structure and charge of an AMP play a major role in the mechanism of its actions. AMPs are generally cationic molecules with both hydrophobic and hydrophilic faces [20]. This amphipathic characteristic helps these molecules to integrate into the lipid bilayer membranes [21]. Membrane integrity disruption (via interaction with negatively charged cell membrane), inhibition of macromolecule (protein, DNA and RNA) synthesis, or interaction with certain intracellular targets are thought to be the primary mechanisms in AMP lethality [22]. Positively charged side chains in AMPs enable an initial nonspecific electrostatic interaction with the negatively charged cell membrane. This process is followed by the insertion of AMP molecule into cell membrane with the help of hydrophobic residues [23]. For example, in the AMPs LL-37 and $\beta$-defensin, the cationic face is positioned on the opposite side of the hydrophobic face, which helps the penetration into the membrane [20].

AMPs afford promising candidates for novel therapeutic agents and complement traditional antibiotic therapies because of some unique advantages, including broad-spectrum activity (antibacterial, antiviral, and antifungal), less resistance by microbes, and related broad anti-inflammatory activities [24]. A number of AMPs and derivatives have been developed as therapies for infectious diseases such as oral mucositis [25], pulmonary infections associated with cystic fibrosis [26], and some sexually transmitted diseases [27]. AMPs can be used alone, in co-treatment with antibiotics, or as stimulators for immune system and toxin inhibiting agents in septic shocks [24].

Despite the aforementioned advantages, wide applications of AMPs are still limited by several factors. They are generally expensive to synthesize [28], vulnerable to proteolytic degradation upon intravenous administration [29] and sensitive to environmental factors such as salt concentration, $\mathrm{pH}$, and the presence of plasma and serum proteins [30]. Another challenge is that some AMPs are cytotoxic to host cells [31].

In order to overcome these challenges, a number of synthetic AMPs and AMP-mimetics have been developed. Based on the concept that cationic charge, size, and lipophilicity are recognized major factors determining the antibacterial activity of AMPs, recently, the Kallenbach lab designed and screened several combinatorial libraries based on 1,3,5-triazine as a scaffold. Several lead compounds with good antimicrobial activity and low hemolytic activity were identified from the screening of hundreds of triazine compounds [32]. With further structure activity relationship analysis, the compound TN-5 was identified as a potent antimicrobial compound (the screening results will be published elsewhere). In this study, TN-5 (Figure 1) was tested for its antimicrobial activity on E. coli and $P$. aeruginosa, including regular planktonic cells, persister cells, and biofilms.

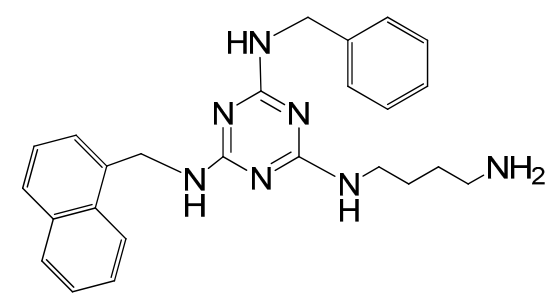

TN-5

Figure 1. Chemical structure of TN-5. 


\section{Results}

\subsection{Minimum Inhibitory Concentration (MIC) and Minimal Bactericidal Concentration (MBC) of TN-5}

TN-5 was found to completely inhibit the growth of E. coli RP437, P. aeruginosa PAO1, and P. aeruginosa PDO300 at the concentration of $12.8 \mu \mathrm{M}$ (MIC, Table 1). The MBC value was found to be higher than $96 \mu \mathrm{M}$ for all three strains.

Table 1. Minimum Inhibitory Concentration (MIC) and Minimal Bactericidal Concentration (MBC) values of TN-5 on bacterial strains used in this study (based on three biological replicates).

\begin{tabular}{cccc}
\hline \multirow{2}{*}{ Antimicrobial Test } & \multicolumn{3}{c}{ Bacterial Strains } \\
\cline { 2 - 4 } & E. coli RP437 & P. aeruginosa PAO1 & P. aeruginosa PDO300 \\
\hline MIC $(\mu \mathrm{M})$ & 12.8 & 12.8 & 12.8 \\
$\operatorname{MBC}(\mu \mathrm{M})$ & $>96$ & $>96$ & $>96$ \\
\hline
\end{tabular}

\subsection{Antimicrobial Effects of TN-5 on Planktonic Cells}

To further study the killing activity of TN-5, exponential cultures were used to test the effects of TN-5 on the viability of planktonic cells. TN-5 was found effective in killing all bacterial strains tested in this study (E. coli RP437, P. aeruginosa PAO1 and PDO300) dose dependently in $3 \mathrm{~h}$ (Figure 2). Longer incubation times (up to $24 \mathrm{~h}$ ) did not cause additional killing (Figure S1). For E. coli RP437, TN-5 showed 20.3\% $\pm 2.5 \%(p=0.07), 55.6 \% \pm 8 \%(p<0.001), 84.6 \% \pm 8.5 \%(p<0.001)$, and $99.9 \% \pm 0.1 \%(3.4 \mathrm{log} ; p<0.001)$ killing of the total population $(>99 \%$ as normal cells) at concentrations of 5, 20,50, and $100 \mu \mathrm{M}$, respectively (Figure 2A). These results show that TN-5 is highly effective against normal planktonic cells of $E$. coli RP437.

Significant killing effects were also observed on planktonic cells of $P$. aeruginosa PAO1 and PDO300 strains. For example, killing of $22.7 \% \pm 6.7 \%(p<0.001), 61.8 \% \pm 4.5 \%(p<0.001), 74.7 \% \pm 11.8 \%$ $(p<0.001)$, and $97.8 \% \pm 10 \%(1.6 \log ; p<0.001)$ of $P$. aeruginosa PAO1 was observed when TN-5 was added at 5, 20, 50, and $100 \mu \mathrm{M}$ respectively (Figure 2B). For P. aeruginosa PDO300, significant killing was observed at 50 and $100 \mu \mathrm{M}$ with $44.1 \% \pm 3.1 \%(p<0.001)$ and $94.1 \pm 6.8 \%(1.23 \log$; $p<0.001$ ) of the total population ( $>99 \%$ as normal cells) killed, respectively (Figure $2 \mathrm{C}$ ). These results show that TN-5 is also effective against normal planktonic cells of $P$. aeruginosa.

\subsection{Antimicrobial Effects of TN-5 on Persister Cells}

TN-5 was found to kill persister cells of E. coli RP437, P. aeruginosa PAO1 and P. aeruginosa PDO300 (Figure 3). The killing of E. coli RP437 persister cells was $33.8 \% \pm 0.8 \%(p<0.001)$, $43.8 \% \pm 2.8 \%(p<0.001)$, and $96.3 \% \pm 3.0 \%(1.35 \log ; p<0.001)$ when TN-5 was added at 50, 100, and $200 \mu \mathrm{M}$, respectively (Figure $3 \mathrm{~A}$ ).

Similarly, TN-5 was also able to reduce the viability of $P$. aeruginosa PAO1 persister cells where $79.6 \% \pm 2.9 \%(p<0.001)$ and $89.9 \% \pm 4.5 \%(p<0.001)$ of cells were killed by $100 \mu \mathrm{M}$ and $200 \mu \mathrm{M}$ of TN-5, respectively (Figure 3B). In comparison, TN-5 was less effective on persister cells of the mucoid strain P. aeruginosa PDO300, with only $33.2 \% \pm 5.6 \%(p<0.001)$ and $36.4 \% \pm 5.2 \%(p<0.001)$ 
killed by $100 \mu \mathrm{M}$ and $200 \mu \mathrm{M}$ of TN-5, respectively (Figure 3C). This is likely due to the presence of alginate on the surface of the mucoid $P$. aeruginosa PDO300 cells [33], which may reduce the penetration by $\mathrm{TN}-5$.

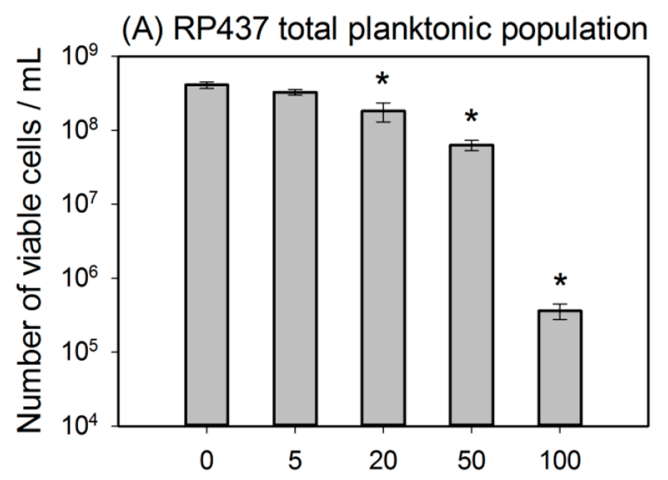

Concentration of TN-5 $(\mu \mathrm{M})$
(B) PAO1 total planktonic population

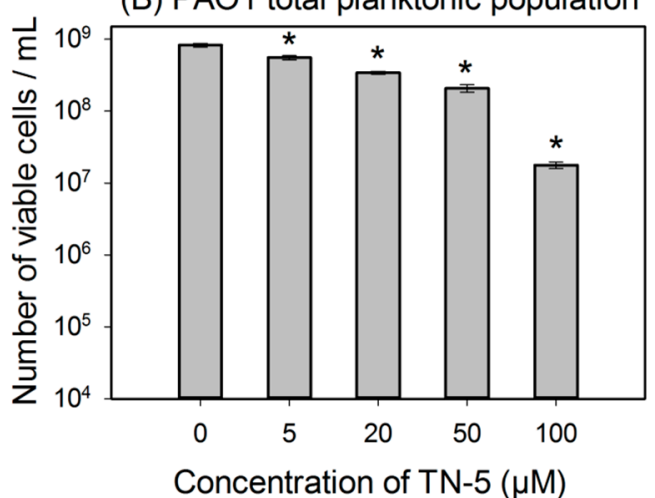

(C) PDO300 total planktonic population

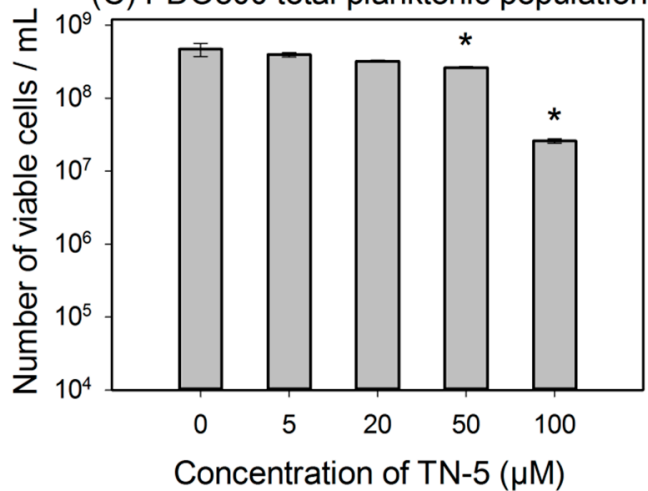

Figure 2. Effects of TN-5 on planktonic cells of E. coli RP437 (A), P. aeruginosa PAO1 (B), and $P$. aeruginosa PDO300 (C). TN-5 was added in exponential phase cultures at different concentrations and the viability after treatment was determined by counting colony forming unit (CFU). All significant differences (compared to the TN-5 free control) with $p<0.01$ are marked with an asterisk.
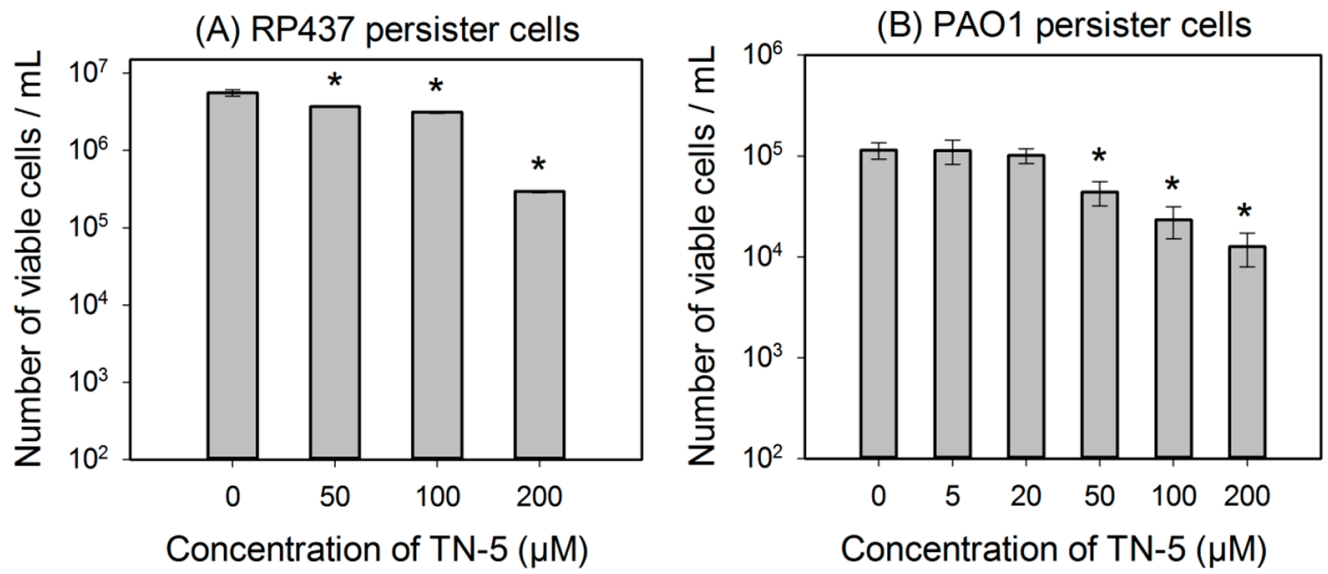

Figure 3. Cont. 


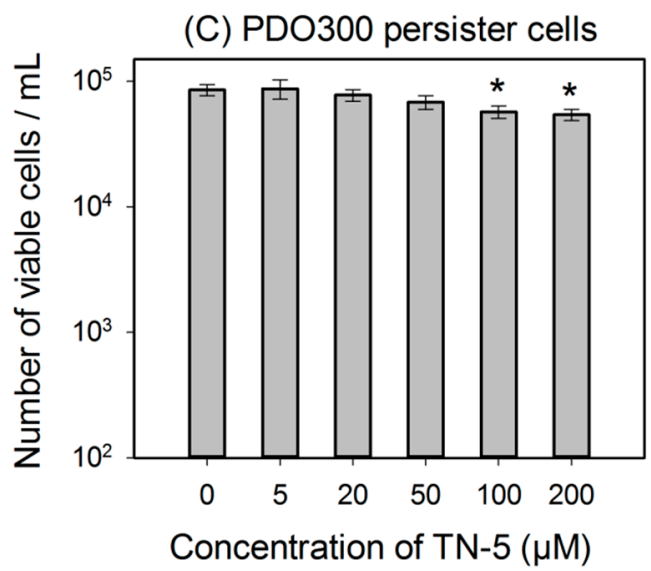

Figure 3. Effects of TN-5 on persister cells of E. coli RP437 (A), P. aeruginosa PAO1 (B), and PDO300 (C). The persister cells were isolated by treating exponential cultures of E. coli RP437 with $100 \mu \mathrm{g} / \mathrm{mL}$ ampicillin and overnight $P$. aeruginosa cultures with $200 \mu \mathrm{g} / \mathrm{mL}$ ciprofloxacin (both for $3 \mathrm{~h}$ ). All significant differences (compared to the TN-5 free control) with $p<0.01$ are marked with an asterisk.

\subsection{Antimicrobial Effects of TN-5 on Biofilm Cells}

TN-5 exhibited effective and dose dependent killing of E. coli RP437 biofilms. Killing of $78.5 \% \pm 30.2 \%(p<0.001)$ and $98.9 \% \pm 9.6 \%(1.24 \log ; p<0.001)$ of $E$. coli RP437 biofilm cells was achieved when TN-5 was added at 100 and $200 \mu \mathrm{M}$, respectively (insignificant at $50 \mu \mathrm{M}$ ) (Figure 4). In addition to the effects on established biofilms of E. coli RP437, TN-5 effectively prevented biofilm formation of all the strains used in this study. Complete biofilm inhibition of E. coli RP437 and P. aeruginosa (both PAO1 and PDO300) was achieved with 10 and $20 \mu \mathrm{M} \mathrm{TN}-5$, respectively (Figure S2). However, $100 \mu \mathrm{M}$ TN-5 alone did not show significant killing of cells in established biofilms of P. aeruginosa PAO1 or PDO300 ( $p>0.1)$ (Figure 5A,C).

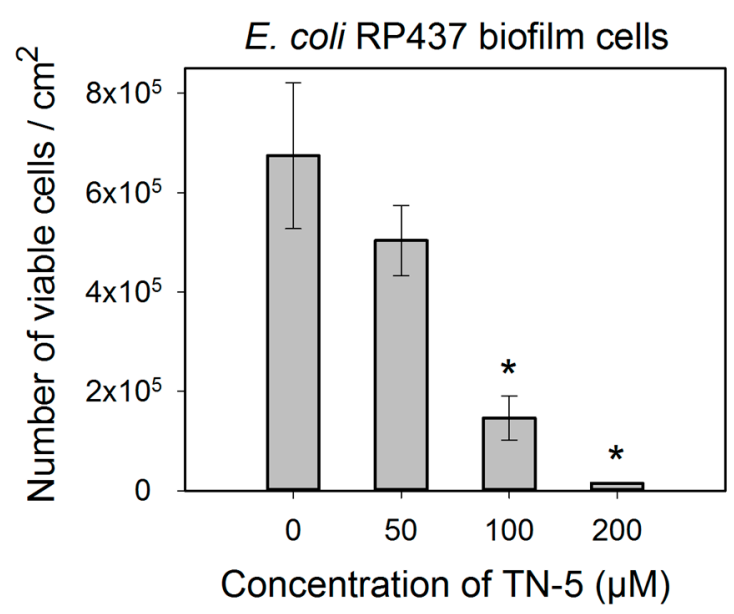

Figure 4. Effects of TN-5 on E. coli RP437 biofilms. The biofilms were cultured for $24 \mathrm{~h}$ in LB on stainless steel coupons prior to treatment with TN-5. All significant differences (compared to the TN-5 free control) with $p<0.01$ are marked with an asterisk. Note: Data are plotted in linear scale. 
(A) Treatment of PDO300 biofilms

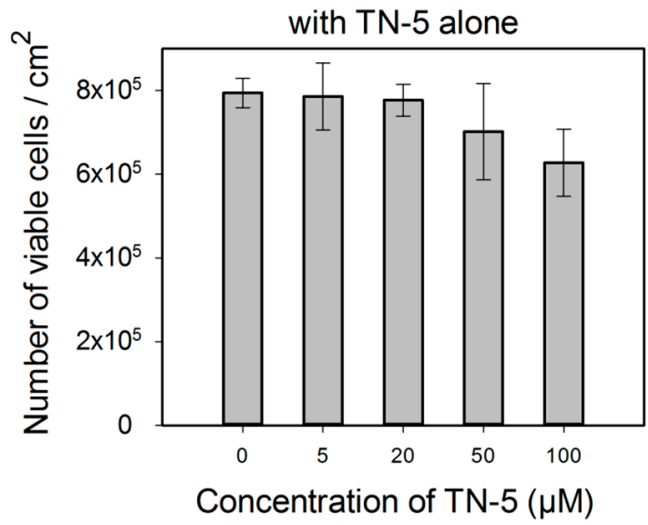

(C) Treatment of PAO1 biofilms with $\mathrm{TN}-5$ alone

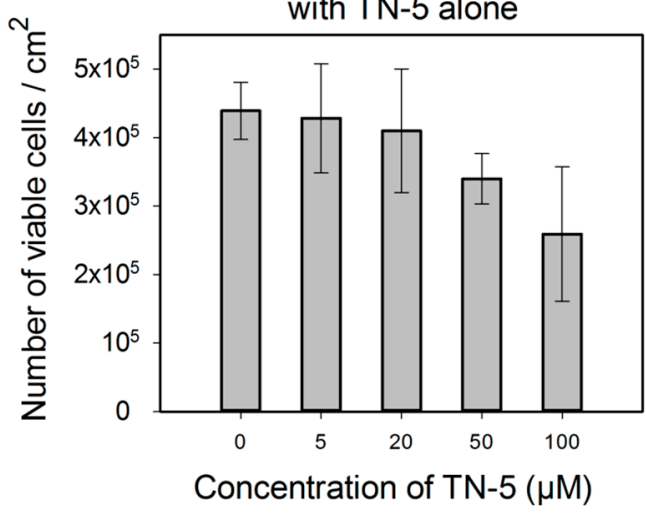

(B) Co-treatment of PDO300 biofilms with $\mathrm{TN}-5$ and alginate lyase

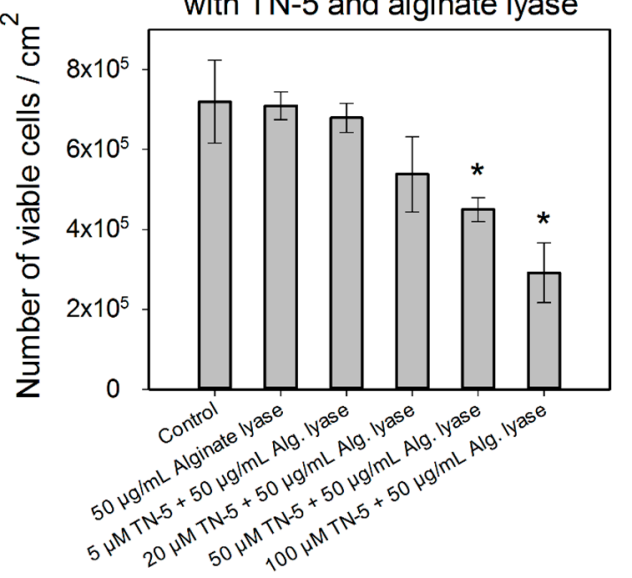

(D) Co-treatment of PAO1 biofilms with $\mathrm{TN}-5$ and alginate lyase

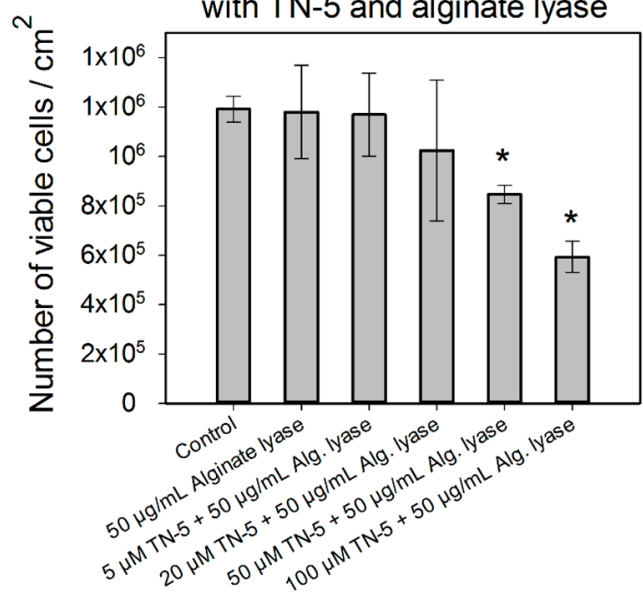

Figure 5. Effects of TN-5 alone and co-treatment with alginate lyase on $P$. aeruginosa PDO300 (A and B) and PAO1 (C and D) biofilms. The biofilms were grown for $24 \mathrm{~h}$ and treated with TN-5 alone or in combination with alginate lyase for $3.5 \mathrm{~h}$. All significant differences (compared with the TN-5 free control) with $p<0.01$ are marked with an asterisk. The co-treatment with $\mathrm{TN}-5$ (at 50 or $100 \mu \mathrm{M}$ ) and $50 \mu \mathrm{g} / \mathrm{mL}$ alginate lyase caused significant killing compared to the control (with no TN-5 and alginate lyase) for both $P$. aeruginosa PDO300 and PAO1, but only significantly increased the killing by TN-5 alone for P. aeruginosa PDO300. Note: Data are plotted in linear scale.

We speculated that the lack of antimicrobial effects against $P$. aeruginosa biofilms is because of the presence of biofilm matrix. Alginate is a major component of biofilm matrix of the mucoid $P$. aeruginosa strains $[13,33]$. Thus we tested the concurrent treatment of $P$. aeruginosa biofilms with alginate lyase and TN-5. As shown in Figure 5B,D, alginate lyase itself showed no effect on the viability of biofilm cells $(p=1)$. However, the combination of TN-5 with alginate lyase increased the killing of PDO300 biofilms; e.g., addition of $50 \mu \mathrm{M}$ alginate lyase increased the activity of $50 \mu \mathrm{M}$ TN-5 on $P$. aeruginosa PDO300 biofilms from no significant killing $(p=0.58)$ to $36.5 \% \pm 4.6 \%(p<0.005)$ and that of $100 \mu \mathrm{M}$ TN-5 from insignificant killing $(p=0.12)$ to $57 \% \pm 9.6 \%(p<0.005)$, respectively (Figure 5A vs. Figure 5B). The addition of alginate lyase did not show the same effects on P. aeruginosa PAO1 biofilm cells; e.g., $50 \mu \mathrm{M}$ alginate lyase did not increase the effects of 50 and $100 \mu \mathrm{M}$ 
TN-5 ( $p>0.1$ ) (by comparing the $\%$ of killing based on corresponding data between Figure 5C,D). This is likely because alginate is not a major component of its biofilm matrix.

\section{Discussion}

AMPs have been proposed as a promising source of new antimicrobial agents [34-37]. Different strategies have been tested to achieve effective killing of microbes while maintaining low hemolytic activity. In some of these studies, Trp and Arg containing 1,3,5-triazine structures [32] and dendrimeric peptides [38] have been used as AMP templates and lead compounds with antimicrobial activities and low toxicity to red blood cells have been identified. In this study, one of the triazine-1,3,5 derivatives, TN-5, was tested on Gram-negative bacteria E. coli and P. aeruginosa. TN-5 was found to be effective against both species. The killing of persister and biofilm cells is of particular interest because these cells are difficult to eliminate and conventional antibiotics are generally ineffective. Our results show that TN-5 alone is effective against persister and biofilms of E. coli RP437 with up to 2-log killing achieved at $200 \mu \mathrm{M}$. It is also interesting that TN-5 caused more killing of biofilm cells than planktonic persister cells of E. coli. For example, $100 \mu \mathrm{M}$ TN-5 killed $43.8 \% \pm 2.8 \%$ and $78.5 \% \pm 30.2 \%$ of persister and biofilm cells of $E$. coli RP437, respectively. This finding suggests that $\mathrm{TN}-5$ can penetrate the biofilm matrix of $E$. coli.

Comparable effects were not observed for $P$. aeruginosa biofilms, however, possibly due to the difference in biofilm matrices. With a thick layer of alginate, biofilms of mucoid bacteria have high-level tolerance to some antimicrobials [13]. Thus, breaking down alginate in the biofilm matrix could be essential for certain antimicrobials to kill biofilm cells, especially the agents that can be absorbed or neutralized by the matrix components. Consistently, we found that the killing of $P$. aeruginosa PDO300 biofilm cells was enhanced by alginate lyase. It is worth noting that TN-5 is effective against $P$. aeruginosa PDO300 persister cells, but not its biofilm cells. Thus, it will be interesting to study if and how TN-5 interacts with alginate directly and if there is any difference in the amount and structure of alginate between biofilm matrix and the surface of mucoid cells. In comparison, the killing of $P$. aeruginosa PAO1 biofilms was not enhanced by alginate lyase. This is consistent with the report [39] that alginate is not the primary component of $P$. aeruginosa PAO1 biofilm matrix. It will be interesting to test other matrix degrading enzymes, such as DNase.

In a previous study performed in our labs, Trp- and Arg- containing synthetic AMPs were shown to inhibit $95.0 \% \pm 1.1 \%$ of $E$. coli biofilm formation at $200 \mu \mathrm{M}$ [40]. Intriguingly, TN-5 inhibited biofilm formation of both E. coli and P. aeruginosa completely at $20 \mu \mathrm{M}$ (Figure S2). Therefore, TN-5 may also be an important antimicrobial agent for biofilm control.

The mechanism of bacterial killing by TN-5 or in fact any AMP deserves more study. The positive charge of the arginine (R) side chain can help an AMP to interact with negatively charged lipopolysaccharides in Gram-negative bacterial walls [41]. Tryptophan (W) residues favor location below the head groups of bilayers, and are assumed to provide lipophilic interaction sites to cause membrane disruption [42]. Thus, RW mimicking TN-5 might target the negatively charged bacterial cell membrane. Another observation is that TN-5 mode of action occurs within the first $3 \mathrm{~h}$ (Figure S1). This rapid mode of action is one of the major features of membrane acting AMPs. 
E. coli is generally more susceptible to antibiotics than $P$. aeruginosa. Among 47 antimicrobial agents tested in an early study [43], only tobramycin showed the same MIC value $(0.5 \mu \mathrm{g} / \mathrm{mL})$ for E. coli (NCTC 10418 and ATCC 25922) and P. aeruginosa (NCTC 10662 and ATCC 27853) reference strains. The other antimicrobial agents tested all showed higher (up to 500 fold) MIC values for $P$. aeruginosa compared to E. coli [43]. Interestingly, TN-5 showed the same MIC value $(12.8 \mu \mathrm{M})$ for both species in our study, which also indicates possible membrane targeting activities.

Overall, this study shows that the triazine derivative $\mathrm{TN}-5$ is a promising lead compound for developing new synthetic AMPs. It is encouraging that TN-5 is effective against both E. coli and $P$. aeruginosa at different growth stages. Persister cells of Pseudomonas strains, especially those of the mucoid strains, are highly resistant to antibiotic treatments. Because most AMPs kill microbes through mechanisms that differ from those of conventional antibiotics, e.g. by targeting cell membranes, the killing effect of TN-5 on persister cells might be increased by synergy with some antibiotics if TN-5 can be effectively delivered to target cells. We assume that triazines are not susceptible to proteolytic degradation since there is no specific motif to trigger cleavage. Future experiments with mammalian cells and animal models are needed to evaluate the potential of using TN-5 and antibiotics together as a novel therapy for chronic infections involving biofilms and persister cells.

\section{Experimental Section}

\subsection{Chemical Synthesis of TN-5}

TN-5, N2-(4-Aminobutyl)-N4-benzyl-N6-naphthalenemethyl-2,4,6-triamino-1,3,5-triazine (Figure 1), white solid, was synthesized using an orthogonal synthetic approach based on cyanuric chloride stepwise reaction with naphthalenemethylamine, benzylamine and Boc-1,4-diaminobutane as documented previously [32]. In brief, (i) cyanuric chloride was mixed with naphthalenemethylamine (1.1 eq) in tetrahydrofuran (THF) at $0{ }^{\circ} \mathrm{C}$, and N,N-diisopropylethylamine (DIEA) (2 eq). After 1 hour of stirring, the solution was extracted with water/ethyl acetate and product 2, 4-dichloro-N6naphthalenemethylamino-1,3,5-triazine was purified using flash column chromatography. (ii) PAL aldehyde resin was mixed with benzylamine (5 eq.) in THF with $2 \%$ of acetic acid and shaked at room temperature for $1 \mathrm{~h}$. At the end of the hour, $\mathrm{NaB}$ (OAc) $3 \mathrm{H}$ (7 eq.) was added and mixed at room temperature overnight. (iii) The product on resin (4 eq) was mixed with 2, 4-dichloro-N6naphthalenemethylamino-1,3,5-triazine in THF and heated at $60{ }^{\circ} \mathrm{C}$ for $3 \mathrm{~h}$. (iv) Resin from last step was mixed with Boc-1,4-Diaminobutane (10 eq) and DIEA (30 eq) in $N$-methylpyrrolidinone- $N$ butanol (NMP: $n$-BuOH) $(1: 1)$ and heated for $3 \mathrm{~h}$ at $120{ }^{\circ} \mathrm{C}$. (v) Resin was cleaved with $10 \%$ TFA in dichloromethane (DCM) for $30 \mathrm{~min}$. Final product was dried and purified with prep thin layer chromatography (TLC). The identity of TN-5 was confirmed by LC-MS (Agilent 6226 TOF LC/MS Mass Spectrometer, Agilent Technologies Inc., Santa Clara, CA, USA). HRMS $m / z$ : calculated $[\mathrm{M}+\mathrm{H}]^{+}$ 428.2557, found 428.2566 (Figure S3). The composition of the product was verified by ${ }^{1} \mathrm{H}-\mathrm{NMR}(300$ $\left.\mathrm{MHz}, \mathrm{CD}_{3} \mathrm{OD}\right): \delta 8.10-7.86(\mathrm{~m}, 1 \mathrm{H}), \delta 7.8-7.65(\mathrm{~m}, 2 \mathrm{H}), \delta 7.55-7.30(\mathrm{~m}, 4 \mathrm{H}), \delta 7.30-7.15(\mathrm{~m}, 3 \mathrm{H})$, $\delta 7.18(\mathrm{~s}, 2 \mathrm{H}), \delta 5.05-4.92(\mathrm{~m}, 2 \mathrm{H}), \delta 4.55-4.40(\mathrm{~m}, 2 \mathrm{H}), \delta 3.40-3.25(\mathrm{~m}, 2 \mathrm{H}), \delta 2.90-2.61(\mathrm{~m}, 2 \mathrm{H})$, $\delta 1.65-1.40(\mathrm{~m}, 4 \mathrm{H})$ (Figure $\mathrm{S} 4)$. 


\subsection{Bacterial Strains and Growth Media}

E. coli RP437 [44] was provided by Dr. John S. Parkinson at the University of Utah. P. aeruginosa PAO1 [45] and P. aeruginosa PDO300 [12] were obtained from Dr. Matthew Parsek at the University of Washington. All strains were routinely grown in Lysogeny broth (LB) containing $10 \mathrm{~g} / \mathrm{L} \mathrm{NaCl}, 5 \mathrm{~g} / \mathrm{L}$ yeast extract, and $10 \mathrm{~g} / \mathrm{L}$ tryptone with $\mathrm{pH}$ 7.0. To ensure consistent experimental conditions throughout this study, all overnight cultures of a particular strain were started with single-use glycerol stocks originating from the same culture. Each experimental condition was tested with three independent cultures (three biological replicates).

\subsection{MIC and MBC Values of TN-5}

TN-5 was tested at different concentrations against E. coli and P. aeruginosa strains to determine MIC and MBC values following a previously described protocol [46] with slight modifications. MIC is referred to the concentration of an antimicrobial agent, which inhibits the visible growth of a given bacterium completely by checking with unaided eye. MBC is referred to the minimum concentration of an antimicrobial agent required to completely kill all the tested bacterial cells of a particular strain by checking colony formation on the plates after treatment. Briefly, exponential cultures of bacterial samples were used to inoculate test samples with a cell density of $5 \times 10^{5}$ colony forming unit $(\mathrm{CFU}) / \mathrm{mL}$. TN-5 was tested at concentrations from $0.2 \mu \mathrm{M}$ to $96 \mu \mathrm{M}$, increasing logarithmically. Cultures grown without antimicrobial and sterile LB medium were used as positive and negative controls, respectively. All samples were adjusted to a final volume of $3 \mathrm{~mL}$ and incubated for $16-18 \mathrm{~h}$ at $37{ }^{\circ} \mathrm{C}$. After incubation, the concentrations with no visible growth were assigned by visual check to determine MIC. MBC value of TN-5 was identified by spreading TN-5 $(0.2 \mu \mathrm{M}$ to $96 \mu \mathrm{M})$ treated cells (overnight in LB) on LB agar plates and checking for growth after $24 \mathrm{~h}$. Three independent cultures for each concentration were tested for MIC and MBC tests.

\subsection{Effects on Planktonic Cells}

To examine the antimicrobial activity of $\mathrm{TN}-5$, the planktonic growth of E. coli RP437, P. aeruginosa PAO1 and PDO300 with TN-5 added at different concentrations was examined. Overnight cultures of each strain were grown in $50 \mathrm{~mL}$ LB medium for $12-16 \mathrm{~h}$ at $37{ }^{\circ} \mathrm{C}$. Subcultures were then prepared by inoculating LB medium with overnight cultures to an optical density at $600 \mathrm{~nm}$ (OD 600$)$ of 0.01 and harvested when the OD600 reached 0.4-0.5. These exponential cultures were washed with phosphate buffered saline (PBS) three times. Cell pellets were washed with fresh PBS and re-suspended in $20 \mathrm{~mL}$ PBS buffer. For the TN-5 treatment, $3 \mathrm{~mL}$ of each sample was taken and mixed with TN-5 at different concentrations. The samples were incubated for 3, 6, 12 and $24 \mathrm{~h}$ at $37{ }^{\circ} \mathrm{C}$ with shaking at $200 \mathrm{rpm}$, and washed three times with PBS. Then a serial dilution of each sample was performed and the cells were spread on LB agar plates for counting CFU. The amount of DMSO (solvent to dissolve TN-5 in stock solutions) was adjusted to be the same for all samples to eliminate any solvent effect. Each condition was tested with three independent cultures. 


\subsection{Persister Isolation and Treatment}

To isolate persister cells, overnight cultures of $P$. aeruginosa PAO1 and P. aeruginosa PDO300 strains were treated with $200 \mu \mathrm{g} / \mathrm{mL}$ ciprofloxacin while exponential cultures of E. coli RP437 were treated with $100 \mu \mathrm{g} / \mathrm{mL}$ ampicillin (all for $3 \mathrm{~h}$ at $37{ }^{\circ} \mathrm{C}$ ) to kill normal cells as described previously [47-49]. Then the persister cells were harvested by centrifugation, washed with PBS three times to remove remaining antibiotic, and re-suspended in $20 \mathrm{~mL}$ PBS. Aliquots $(1 \mathrm{~mL})$ of each sample were supplemented with TN-5 at different concentrations. Three replicates were tested for each condition and all samples were incubated for $3 \mathrm{~h}$ at $37{ }^{\circ} \mathrm{C}$ with shaking at $200 \mathrm{rpm}$. No change in persister cell number was found before and after incubation for 3 and $6 \mathrm{~h}$ in PBS without TN-5 (regardless the presence of antibiotics; Figure S5). After TN-5 treatment, the samples were washed with PBS three times and plated to count CFU as described above. Each condition was tested with three independent cultures.

\subsection{Biofilm Experiments}

To study the effects of TN-5 on biofilm cells of E. coli and P. aeruginosa, biofilms were grown on $2 \mathrm{~cm} \times 1 \mathrm{~cm} \mathrm{316L}$ stainless steel coupons. Each coupon was polished with 220 Grit sandpaper (3M, Sandblaster, St. Paul, MN, USA) on both sides and sterilized with $70 \%$ ethanol for at least $15 \mathrm{~min}$. The coupons were then dried in a $50{ }^{\circ} \mathrm{C}$ oven for $15 \mathrm{~min}$. Sterilization was confirmed by incubating three coupons in LB medium for $24 \mathrm{~h}$ at $37{ }^{\circ} \mathrm{C}$ and checking the turbidity of the cultures. To culture biofilms, sterilized coupons were transferred into new sterile plates containing $20 \mathrm{~mL}$ LB medium. To initiate biofilm formation, each sample was inoculated to $\mathrm{OD}_{600}$ of 0.01 with an overnight culture. The coupons were incubated for $24 \mathrm{~h}$ at $37^{\circ} \mathrm{C}$ without shaking to grow biofilms. After $24 \mathrm{~h}$ incubation the coupons were washed gently with PBS three times to remove planktonic cells. Coupons were then placed in 12 well plates separately, each including a different concentration of TN-5 in $2 \mathrm{~mL}$ PBS buffer. The coupons were incubated for $3 \mathrm{~h}$ at $37^{\circ} \mathrm{C}$ with no shaking followed by washing with PBS three times. Each coupon was then transferred into a $15 \mathrm{~mL}$ sterile conical test tube containing $3 \mathrm{~mL}$ PBS. Samples were gently sonicated for $4 \mathrm{~min}$ in a water sonication bath (Branson B200 Ultrasonic, Danbury, CT, USA) and then vortexed for $15 \mathrm{~s}$. Three replicates were tested for each condition. The cells in the suspension were then spread on LB agar plates to count CFU as described above. Each condition was tested with three independent cultures.

Besides treating established biofilms, the capability of TN-5 to prevent biofilm formation was also evaluated by adding TN-5 prior to the inoculation of biofilm cultures. After incubation for $24 \mathrm{~h}$, the coupons were washed gently and the cells were removed from coupon surface by sonication and vortex for CFU count as described above.

\subsection{Alginate Lyase Enhanced the Effects of TN-5 on P. aeruginosa Biofilm Cells}

To determine the contribution of a biofilm degrading agent in bacterial killing by TN-5, we repeated biofilm killing experiments in the presence of $50 \mu \mathrm{g} / \mathrm{mL}$ alginate lyase during $\mathrm{TN}-5$ treatments. The same protocols were used for P. aeruginosa PAO1 and PDO300 biofilms. Each condition was tested with three independent cultures. 


\subsection{Statistical Analysis}

The data from CFU experiments were analyzed with one-way ANOVA followed by Tukey test using SAS version 9.4 (SAS Institute, Cary, NC, USA). Differences with $p<0.01$ were considered as statistically significant.

\section{Acknowledgements}

We thank John S. Parkinson at University of Utah for sharing the strain E. coli RP437 and Matthew Parsek at University of Washington for providing the $P$. aeruginosa PAO1 and PDO300 strains.

\section{Author Contributions}

A.A.B., Z.L., N.K., and D.R. conceived and designed the experiments; A.A.B., Z.L., and M.G. performed the experiments; A.A.B. and Z.L. analyzed the data; A.A.B and D.R. led the preparation of the manuscript with participation of all authors.

\section{Conflicts of Interest}

The authors declare no conflict of interest.

\section{References}

1. Fleming, A. On the antibacterial action of cultures of a Penicillium, with special reference to their use in the isolation of B. influenzae. Brit. J. Exp. Pathol. 1929, 10, 226-236.

2. Myers, R.S.; Aldrich, R.H.; Howard, R.W.; Walsh, R.A. The use of gauze inoculated with Penicillium notatum or impregnated with crude penicillin in the treatment of surface infections. New Engl. J. Med. 1944, 231, 761-764.

3. Kardos, N.; Demain, A.L. Penicillin: The medicine with the greatest impact on therapeutic outcomes. Appl. Microbiol. Biotechnol. 2011, 92, 677-687.

4. Witte, W.; Cuny, C.; Klare, I.; Nubel, U.; Strommenger, B.; Werner, G. Emergence and spread of antibiotic-resistant Gram-positive bacterial pathogens. Int. J. Med. Microbiol. 2008, 298, 365-377.

5. O’Connell, K.M.; Hodgkinson, J.T.; Sore, H.F.; Welch, M.; Salmond, G.P.; Spring, D.R. Combating multidrug-resistant bacteria: Current strategies for the discovery of novel antibacterials. Angew. Chem. Int. Ed. 2013, 52, 10706-10733.

6. Davies, J. Inactivation of antibiotics and the dissemination of resistance genes. Science 1994, 264, 375-382.

7. Lewis, K. Persister cells: Molecular mechanisms related to antibiotic tolerance. In Antibiotic Resistance; Springer Berlin Heidelberg: Berlin, Germany, 2012; Volume 211, pp. 121-133.

8. Lewis, K. Riddle of biofilm resistance. Antimicrob. Agents Chemother. 2001, 45, 999-1007.

9. Barlow, M. What antimicrobial resistance has taught us about horizontal gene transfer. Methods Mol. Biol. 2009, 532, 397-411.

10. Lewis, K. Persister cells, dormancy and infectious disease. Nat. Rev. Microbiol. 2007, 5, 48-56. 
11. Hall-Stoodley, L.; Costerton, J.W.; Stoodley, P. Bacterial biofilms: From the natural environment to infectious diseases. Nat. Rev. Microbiol. 2004, 2, 95-108.

12. Mathee, K.; Ciofu, O.; Sternberg, C.; Lindum, P.W.; Campbell, J.I.; Jensen, P.; Johnsen, A.H.; Givskov, M.; Ohman, D.E.; Molin, S.; et al. Mucoid conversion of Pseudomonas aeruginosa by hydrogen peroxide: A mechanism for virulence activation in the cystic fibrosis lung. Microbiology 1999, 145, 1349-1357.

13. Pritt, B.; O’Brien, L.; Winn, W. Mucoid Pseudomonas in cystic fibrosis. Am. J. Clin. Pathol. 2007, 128, 32-34.

14. Cabral, D.A.; Loh, B.A.; Speert, D.P. Mucoid Pseudomonas aeruginosa resists nonopsonic phagocytosis by human neutrophils and macrophages. Pediatr. Res. 1987, 22, 429-431.

15. Govan, J.R.; Harris, G.S. Pseudomonas aeruginosa and cystic fibrosis: Unusual bacterial adaptation and pathogenesis. Microbiol. Sci. 1986, 3, 302-308.

16. Torcato, I.M.; Huang, Y.H.; Franquelim, H.G.; Gaspar, D.; Craik, D.J.; Castanho, M.A.; Henriques, S.T. Design and characterization of novel antimicrobial peptides, R-BP100 and RW-BP100, with activity against Gram-negative and Gram-positive bacteria. Biomembranes 2013, 1828, 944-955.

17. Chongsiriwatana, N.P.; Wetzler, M.; Barron, A.E. Functional synergy between antimicrobial peptoids and peptides against Gram-negative bacteria. Antimicrob. Agents Ch. 2011, 55, 5399-5402.

18. Wiesner, J.; Vilcinskas, A. Antimicrobial peptides the ancient arm of the human immune system. Virulence 2010, 1, 440-464.

19. Wang, G. Human antimicrobial peptides and proteins. Pharmaceuticals 2014, 7, 545-594.

20. Izadpanah, A.; Gallo, R.L. Antimicrobial peptides. J. Am. Acad. Dermatol. 2005, 52, 381-390.

21. Jenssen, H.; Hamill, P.; Hancock, R.E. Peptide antimicrobial agents. Clin. Microbiol. Rev. 2006, 19, 491-511.

22. Bahar, A.A.; Ren, D. Antimicrobial peptides. Pharmaceuticals 2013, 6, 1543-1575.

23. Madani, F.; Lindberg, S.; Langel, U.; Futaki, S.; Graslund, A. Mechanisms of cellular uptake of cell-penetrating peptides. J. Biophys. 2011, 2011, 414729.

24. Gordon, Y.J.; Romanowski, E.G.; McDermott, A.M. A review of antimicrobial peptides and their therapeutic potential as anti-infective drugs. Curr. Eye Res. 2005, 30, 505-515.

25. Donnelly, J.P.; Bellm, L.A.; Epstein, J.B.; Sonis, S.T.; Symonds, R.P. Antimicrobial therapy to prevent or treat oral mucositis. Lancet Infect. Dis. 2003, 3, 405-412.

26. Zhang, L.; Parente, J.; Harris, S.M.; Woods, D.E.; Hancock, R.E.; Falla, T.J. Antimicrobial peptide therapeutics for cystic fibrosis. Antimicrob. Agents Chemother. 2005, 49, 2921-2927.

27. Yedery, R.D.; Reddy, K.V. Antimicrobial peptides as microbicidal contraceptives: Prophecies for prophylactics - a mini review. Eur. J. Contracep. Repr. 2005, 10, 32-42.

28. Laverty, G.; Gorman, S.P.; Gilmore, B.F. The potential of antimicrobial peptides as biocides. Int. J. Mol. Sci. 2011, 12, 6566-6596.

29. Noto, P.B.; Abbadessa, G.; Cassone, M.; Mateo, G.D.; Agelan, A.; Wade, J.D.; Szabo, D.; Kocsis, B.; Nagy, K.; Rozgonyi, F.; et al. Alternative stabilities of a proline-rich antibacterial peptide in vitro and in vivo. Protein Sci. 2008, 17, 1249-1255. 
30. Bruhn, O.; Grotzinger, J.; Cascorbi, I.; Jung, S. Antimicrobial peptides and proteins of the horse-insights into a well-armed organism. Vet. Res. 2011, 42, 98.

31. Lehrer, R.I.; Lichtenstein, A.K.; Ganz, T. Defensins: Antimicrobial and cytotoxic peptides of mammalian cells. Annu. Rev. Immunol. 1993, 11, 105-128.

32. Zhou, C.H.; Min, J.K.; Liu, Z.G.; Young, A.; Deshazer, H.; Gao, T.; Chang, Y.T.; Kallenbach, N.R. Synthesis and biological evaluation of novel 1,3,5-triazine derivatives as antimicrobial agents. Bioorg. Med. Chem. Lett. 2008, 18, 1308-1311.

33. Hay, I.D.; Remminghorst, U.; Rehm, B.H. MucR, a novel membrane-associated regulator of alginate biosynthesis in Pseudomonas aeruginosa. Appl. Environ. Microbiol. 2009, 75, 1110-1120.

34. Som, A.; Vemparala, S.; Ivanov, I.; Tew, G.N. Synthetic mimics of antimicrobial peptides. Biopolymers 2008, 90, 83-93.

35. Thaker, H.D.; Som, A.; Ayaz, F.; Lui, D.; Pan, W.; Scott, R.W.; Anguita, J.; Tew, G.N. Synthetic mimics of antimicrobial peptides with immunomodulatory responses. J. Am. Chem. Soc. 2012, 134, 11088-11091.

36. He, J.; Eckert, R.; Pharm, T.; Simanian, M.D.; Hu, C.; Yarbrough, D.K.; Qi, F.; Anderson, M.H.; Shi, W. Novel synthetic antimicrobial peptides against Streptococcus mutans. Antimicrob. Agents Chemother. 2007, 51, 1351-1358.

37. Diehnelt, C.W. Peptide array based discovery of synthetic antimicrobial peptides. Front. Microbiol. 2013, 4, 402.

38. Bahar, A.A.; Liu, Z.; Totsingan, F.; Buitrago, C.; Kallenbach, N.; Ren, D. Synthetic dendrimeric peptide active against biofilm and persister cells of Pseudomonas aeruginosa. Appl. Microbiol. Biotechnol. 2015, 99, 8125-8135.

39. Wozniak, D.J.; Wyckoff, T.J.; Starkey, M.; Keyser, R.; Azadi, P.; O’Toole, G.A.; Parsek, M.R. Alginate is not a significant component of the extracellular polysaccharide matrix of PA14 and PAO1 Pseudomonas aeruginosa biofilms. Proc. Natl. Acad. Sci. USA 2003, 100, 7907-7912.

40. Hou, S.Y.; Liu, Z.G.; Young, A.W.; Mark, S.L.; Kallenbach, N.R.; Ren, D.C. Effects of Trp- and Arg-containing antimicrobial peptide structure on inhibition of Escherichia coli planktonic growth and biofilm formation. Appl. Environ. Microbiol. 2010, 76, 1967-1974.

41. Brown, K.L.; Hancock, R.E. Cationic host defense (antimicrobial) peptides. Curr. Opin. Immunol. 2006, 18, 24-30.

42. Tam, J.P.; Lu, Y.A.; Yang, J.L. Antimicrobial dendrimeric peptides. Eur. J. Biochem. 2002, 269, 923-932.

43. Andrews, J.M. Determination of minimum inhibitory concentrations. J. Antimicrob. Chemother. 2001, 48, 5-16.

44. Parkinson, J.S.; Houts, S.E. Isolation and behavior of Escherichia coli deletion mutants lacking chemotaxis functions. J. Bacteriol. 1982, 151, 106-113.

45. DeVries, C.A.; Ohman, D.E. Mucoid-to-nonmucoid conversion in alginate-producing Pseudomonas aeruginosa often results from spontaneous mutations in algt, encoding a putative alternate sigma factor, and shows evidence for autoregulation. J. Bacteriol. 1994, 176, 6677-6687.

46. Wiegand, I.; Hilpert, K.; Hancock, R.E. Agar and broth dilution methods to determine the minimal inhibitory concentration (MIC) of antimicrobial substances. Nat. Protoc. 2008, 3, 163-175. 
47. Niepa, T.H.R.; Gilbert, J.L.; Ren, D.C. Controlling Pseudomonas aeruginosa persister cells by weak electrochemical currents and synergistic effects with tobramycin. Biomaterials 2012, 33, 7356-7365.

48. Pan, J.C.; Bahar, A.A.; Syed, H.; Ren, D.C. Reverting antibiotic tolerance of Pseudomonas aeruginosa PAO1 persister cells by (Z)-4-bromo-5-(bromomethylene)-3-methylfuran-2(5H)-one. PloS ONE 2012, 7, e45778.

49. Chen, X.; Zhang, M.; Zhou, C.H.; Kallenbach, N.R.; Ren, D.C. Control of bacterial persister cells by Trp/Arg-containing antimicrobial peptides. Appl. Environ. Microbiol. 2011, 77, 4878-4885.

(C) 2015 by the authors; licensee MDPI, Basel, Switzerland. This article is an open access article distributed under the terms and conditions of the Creative Commons Attribution license (http://creativecommons.org/licenses/by/4.0/). 